\title{
Molecular Characteristics, Synthase, and Food Application of Cereal $\beta$-Glucan
}

\author{
Lijing Sun, Mengyun Hu, Jie Zhao, Liangjie Lv, Yelun Zhang, Qian Liu, Li Zhang, \\ Cuihong Yu, Peinan Wang, Qianying Li, Hui Li $(\mathbb{D}$, and Yingjun Zhang $(\mathbb{D}$
}

\author{
Institute of Cereal and Oil Crops, Hebei Academy of Agriculture and Forestry Sciences, \\ Hebei Laboratory of Crop Genetics and Breeding, Shijiazhuang, China \\ Correspondence should be addressed to Hui Li; zwslihui@163.com and Yingjun Zhang; zhangyingjun1977@163.com
}

Received 17 December 2020; Revised 2 February 2021; Accepted 8 February 2021; Published 8 March 2021

Academic Editor: wujun Ma

Copyright (c) 2021 Lijing Sun et al. This is an open access article distributed under the Creative Commons Attribution License, which permits unrestricted use, distribution, and reproduction in any medium, provided the original work is properly cited.

Cereal $\beta$-glucan is a type of valuable dietary fiber that mainly exists in the aleurone, subaleurone, and endosperm of some cereal grains. $\beta$-Glucan is acknowledged as a functional food ingredient owing to its multiple health benefits, including the prevention of diabetes, reduction in the incidence of cardiovascular disease, antitumor effects, antioxidant activities, and immunostimulation. It is well documented that cellulose synthase-like $C s l F / H / J$ genes encode synthases responsible for $\beta$-glucan biosynthesis in cereal grains. Recently, $\beta$-glucan has been widely applied as an emulsion stabilizer, thickening agent, fat substitute, and bioactive ingredient in the food industry due to its water solubility, viscosity, gelation property, and health benefits. Therefore, the present paper aims to review the molecular characteristics, synthase gene family, and food application of cereal $\beta$-glucan in recent years.

\section{Introduction}

$\beta$-Glucan (also known as mixed linkage glucan) is a longchain polysaccharide consisting of D-glucose monomers linked via $\beta$-glycosidic bonds. It is a type of valuable dietary fiber that is widely present in cereals, mushrooms, seaweeds, yeast, and some bacteria $[1,2]$. The glycosidic linkages in cereal $\beta$-glucan are a combination of $\beta-1,3$ and $\beta-1,4$ glycosidic linkages; hence, it is called $(1,3 ; 1,4)$ - $\beta$-glucan. The glycosidic linkages in $\beta$-glucan from other sources are a combination of $\beta-1,3$ and $\beta-1,6$ glycosidic linkages; thus, it is called $(1,3 ; 1,6)-\beta$-glucan [3]. On the basis of the above molecular structure, $\beta$-glucan has a high water binding capacity, resulting in its physicochemical properties, such as solubility, viscosity, and gelation.

$\beta$-Glucan is acknowledged as a functional food ingredient owing to its multiple health benefits, including the prevention of diabetes, reduction in the incidence of cardiovascular disease, antitumor effects, antioxidant activities, and immunostimulation [4]. $\beta$-Glucan has a positive effect on the management of diabetes by reducing postprandial plasma glucose and insulin levels $[5,6]$. It is well documented that consuming $\beta$-glucan can lower the risk of coronary heart disease by significantly reducing serum cholesterol levels $[7,8]$. Moreover, $\beta$-glucan has long been considered an important antitumor agent for its immunestimulatory and immunomodulatory effects [9]. Recent studies have validated that $\beta$-glucan can inhibit the viability and metastasis of cancer cells $[10,11]$ and promote cancer cell apoptosis [12]. $\beta$-Glucan also exerts an immunostimulatory effect by the activation of the mucosal immune system through $\beta$-glucan receptor dectin-1 on macrophages [13]. Due to the various health benefits of $\beta$-glucan, many countries, including the United States, the European Union, Canada, Australia, New Zealand, Brazil, and South Korea, have authorized claims to recommend the daily consumption of $\beta$-glucan at least $3 \mathrm{~g}$ per day or $0.6-1 \mathrm{~g}$ per serving [14]. To the best of our knowledge, China has not authorized similar health claims hitherto.

The reported functions of $\beta$-glucan have encouraged researchers to investigate the incorporation of $\beta$-glucan in various kinds of foods to make functional foods. Furthermore, there has been a breakthrough in the research of $\beta$-glucan synthase during the past fifteen years. A 
comprehensive understanding of the synthase gene family will lay the foundation for improving the $\beta$-glucan content in cereals. Hence, the present paper aims to review the molecular characteristics, synthase gene family, and food application of cereal $\beta$-glucan in recent years.

\section{Common Sources and Molecular Characteristics of Cereal $\beta$-Glucan}

$\beta$-Glucan is predominantly found in the aleurone, subaleurone, and endosperm of some cereals (barley and oat). Cereal $\beta$-glucan is a linear polymer of a D-glucose unit that contains two to three consecutive $\beta-1,4$ linkages separated by a $\beta-1,3$ linkage. Many features of $\beta$-glucan are different among cereals, such as content, molecular size, and molar ratio (DP3/DP4) (Table 1).

2.1. Common Sources of Cereal $\beta$-Glucan. Among cereals, barley and oat have the highest $\beta$-glucan content, ranging from $2.2 \%$ to $19.8 \%$ and $2.2 \%-7.8 \%$, respectively $[3,15,16,18]$. Other cereals, such as wheat, rice, and maize, also contain $\beta$-glucan but in much lower amounts (Table 1). Previous studies have demonstrated that variations in $\beta$-glucan content are mainly caused by species and cultivars. Although the $\beta$-glucan content in ordinary barley cultivars is between $4 \%$ and $11 \%$ [26], a genotype containing as high as $19.8 \%$ has been reported [16]. In addition to species and cultivars, environmental conditions also have a significant effect on $\beta$-glucan content. Some studies have verified that warm and dry weather conditions enhance the $\beta$-glucan content $[27,28]$. Given that a great amount of $\beta$-glucan is located in the outer layer of the grain, such as aleurone and subaleurone, the processing is another factor that affects the final $\beta$-glucan content in addition to the factors mentioned above. It is noteworthy to mention that $\beta$-glucan is distributed primarily in the endosperm in barley grains in comparison to in the aleurone layers of oat grains; thus, pearling has little effect on the $\beta$-glucan content in barley $[29,30]$.

2.2. Molecular Weight of Cereal $\beta$-Glucan. The molecular weight of $\beta$-glucan is reported to be scattered in the range of $31-2700 \times 10^{3}$ in barley, $65-3100 \times 10^{3}$ in oat, $21-1100 \times 10^{3}$ in rye, $43-758 \times 10^{3}$ in wheat, and $36 \times 10^{3}$ in sorghum $[17,19]$. The big variations in the molecular weight of $\beta$-glucan are attributed to varietal and environmental factors, extraction and purification protocols, and analytical methodologies $[2,26]$. The molecular weight of $\beta$-glucan can largely determine some other physical characteristics, such as viscosity and solubility, thereby affecting its functional properties. Previous research has indicated that high molecular weight (HMW) barley $\beta$-glucan can delay gastric emptying due to increased viscosity, resulting in a reduced glycemic response and diet-induced thermogenesis [31]. Otherwise, low molecular weight (LMW) barley $\beta$-glucan was ineffective in lowering glycemic responses [32]. Wang et al. demonstrated that the consumption of HMW barley $\beta$-glucan rather than that of LMW $\beta$-glucan altered the composition of gut microbiota and consequently reduced the risk markers of cardiovascular disease [33].

2.3. Molar Ratio of Cereal $\beta$-Glucan. The structure of cereal $\beta$-glucan, also known as $(1,3 ; 1,4)$ - $\beta$-glucan, can be defined by digestion with specific $(1,3 ; 1,4)-\beta$-glucan endohydrolase, which only hydrolyzes the $\beta-1,4$ linkage adjacent to the $\beta-1,3$ linkage, releasing oligosaccharides with a degree of polymerization (DP) of mainly DP3 (cellotriose) and DP4 (cellotetraose) $[34,35]$. The molar ratio of DP3/DP4 is quite variable among cereals (Table 1 ). In addition to species, the molar ratio is associated with genotype and growth environment. High $\beta$-glucan cultivar and drier environment have led to a lower molar ratio in oat [36]. The molar ratio is a unique feature of each cereal, and it affects the solubility and the viscosity of $\beta$-glucan in the solution. For instance, oat $\beta$-glucan with a lower molar ratio $(1.5-2.3)$ is more soluble than barley and wheat $\beta$-glucan with a higher molar ratio (2.6 and 3.2) [25].

\section{3. $\beta$-Glucan Synthase in Cereals}

During the past fifteen years, considerable progress has been made in the synthesis mechanism of $\beta$-glucan. The quantitative trait loci (QTL) for the $\beta$-glucan content of barley grains have been identified extensively, such as the major QTL on chromosome $2 \mathrm{H}[37,38], 3 \mathrm{H}$ [38], $4 \mathrm{H}$ [39], and 7H [40-43]. The $\beta$-glucan synthase gene families have been reported in rice, barley, wheat, oat, maize, and sorghum (Table 2). By comparative genomics analysis between rice and barley, six cellulose synthase-like $C s l F$ genes have been found in the syntenic region that is a major QTL for $\beta$-glucan content on barley chromosome $2 \mathrm{H}$. After the introduction of two of these CslF genes (OsCslF2 and OsCslF4) to Arabidopsis, a species without $C s l F$ genes and $\beta$-glucan, the low $\beta$-glucan levels have been detected by a $\beta$-glucan-specific antibody, indicating the participation of OsCslF genes in $\beta$-glucan biosynthesis [44]. Through a similar experimental approach, cellulose synthase-like $\mathrm{HvCslH1}$ [51] and cellulose synthase-like HvCslJ [52] have also been proved to be capable of directing $\beta$-glucan synthesis.

CslF6, the most highly and widely expressed CslF gene in barley, wheat, and rice [53-57], is the predominant gene for the synthesis of the majority of $\beta$-glucan in cereals. Three independent barley $\beta$-glucanless mutants have shown the cosegregation of the $\beta$-glucan deficiency phenotype with the single nucleotide mutation in $\mathrm{H} v \mathrm{CslF}$ coding sequence (CDS) region, demonstrating a unique role for $\mathrm{HvCslF6}$ in $\beta$-glucan biosynthesis $[48,49]$. This has been further confirmed by the transient expression of wild-type $\mathrm{HvCslF6}$ (which can synthesize $\beta$-glucan) and mutant $\mathrm{HvCslF6}$ (which cannot synthesize $\beta$-glucan) in Nicotiana benthamiana ( $N$. benthamiana) leaves [49]. Additionally, the overexpression of $\mathrm{HvCslF6}$ under the control of an endosperm-specific promoter has increased the $\beta$-glucan content and altered its fine structure in barley grains [47]. On the contrary, the downregulation of TaCslF6 by RNA interference (RNAi) has resulted in decreased $\beta$-glucan content in 
TABLE 1: Common sources and molecular characteristics of cereal $\beta$-glucan.

\begin{tabular}{lcccc}
\hline Source & Content $(\% \mathrm{w} / \mathrm{w})$ & Molecular weight $(\mathrm{g} / \mathrm{mol})$ & Molar ratio $(\mathrm{DP} 3 / \mathrm{DP} 4)$ & References \\
\hline Barley & $2.2-19.8$ & $31-2700 \times 10^{3}$ & $1.8-3.5$ & $1.5-2.3$ \\
Oat & $2.2-7.8$ & $65-3100 \times 10^{3}$ & $1.9-3.0$ & {$[15-17]$} \\
Rye & $1.0-2.7$ & $21-1100 \times 10^{3}$ & $2.8-4.5$ & {$[3,17,18]$} \\
Wheat & $0.18-1.8$ & $43-758 \times 10^{3}$ & $2.1-3.0$ & {$[17,19]$} \\
Sorghum & $0.1-1.7$ & $36 \times 10^{3}$ & 2.5 & {$[17,20-22]$} \\
Maize & $0.8-1.7$ & - & 1.18 & {$[19,23]$} \\
Rice & $0.02-0.13$ & - & $24,25]$ \\
\hline
\end{tabular}

TABLE 2: List of genes confirmed to function in $\beta$-glucan synthesis in cereals.

\begin{tabular}{|c|c|c|c|c|c|c|}
\hline Gene & Promoter & $\begin{array}{l}\text { Gene } \\
\text { source }\end{array}$ & Transgenic host & Approach & Function & Reference \\
\hline OsCslF2 & CaMV $35 S$ & Rice & Arabidopsis & $\mathrm{HE}$ & Synthesize $\beta$-glucan $\leq 0.1 \%(\mathrm{w} / \mathrm{w})$ in leaves. & {$[44]$} \\
\hline OsCslF4 & CaMV $35 S$ & Rice & Arabidopsis & $\mathrm{HE}$ & $\begin{array}{l}\text { Synthesize } \beta \text {-glucan } \leq 0.1 \%(\mathrm{w} / \mathrm{w}) \text { in leaves. } \\
\text { Accumulate high-level } \beta \text {-glucan with poor }\end{array}$ & {$[44]$} \\
\hline OsCslF6 & $\begin{array}{l}\text { CaMV 35S; secondary } \\
\text { cell wall-specific; } \\
\text { senescence-associated }\end{array}$ & Rice & Arabidopsis & $\mathrm{HE}$ & $\begin{array}{l}\text { growth by the } 35 \mathrm{~S} \text { and secondary cell wall } \\
\text { promoter; accumulate high-level } \beta \text {-glucan with } \\
\text { normal growth by the senescence-associated } \\
\text { promoter. }\end{array}$ & {$[45]$} \\
\hline OsCslF6 & - & Rice & - & Mutant & Reduce more than $97 \% \beta$-glucan. & {$[46]$} \\
\hline $\mathrm{HvCslF4}$ & CaMV 35S & Barley & Barley & $\mathrm{OE}$ & $\begin{array}{c}\text { Increase up to } 50 \% \beta \text {-glucan in grain and raise } \\
\text { the DP3 / DP4 ratio. }\end{array}$ & {$[47]$} \\
\hline$H v C s l F 6$ & - & Barley & - & Mutant & $\begin{array}{l}\text { Completely lack } \beta \text {-glucan in the endosperm } \\
\text { and aleurone layers of cell walls. }\end{array}$ & {$[48,49]$} \\
\hline$H v C s l F 6$ & $\begin{array}{l}\text { CaMV 35S; endosperm- } \\
\text { specific }\end{array}$ & Barley & Barley & $\mathrm{OE}$ & $\begin{array}{l}\text { Increase high-level } \beta \text {-glucan in leaves but has } \\
\text { little effect on gain } \beta \text {-glucan by the } 35 \mathrm{~S} \\
\text { promoter; increase more than } 80 \% \beta \text {-glucan in } \\
\text { grains and reduce the DP3/DP } 4 \text { ratio by the } \\
\text { endosperm-specific promoter. }\end{array}$ & {$[47]$} \\
\hline$H v C s l F 6$ & CaMV $35 S$ & Barley & N. benthamiana & $\mathrm{HE}$ & $\begin{array}{l}\text { Synthesize } \beta \text {-glucan about } 1.62 \%(\mathrm{w} / \mathrm{w}) \text { in } \\
\text { leaves with a DP3/DP4 ratio of } 1.40 \text {. }\end{array}$ & {$[21]$} \\
\hline$H v C s l F 6$ & - & Barley & Barley & Knockout & Reduce more than $97 \% \beta$-glucan in grains. & {$[50]$} \\
\hline$H v C s l H 1$ & CaMV $35 S$ & Barley & Arabidopsis & HE & $\begin{array}{c}\text { Synthesize } \beta \text {-glucan } 0.00015 \%-0.016 \%(\mathrm{w} / \mathrm{w}) \\
\text { in leaves and stems. }\end{array}$ & {$[51]$} \\
\hline$H v C s l J$ & CaMV $35 S$ & Barley & N. benthamiana & $\mathrm{HE}$ & Synthesize $\beta$-glucan $\leq 0.1 \%(\mathrm{w} / \mathrm{w})$ in leaves. & {$[52]$} \\
\hline TaCslF6 & Endosperm-specific & Wheat & Wheat & RNAi & $\begin{array}{c}\text { Decrease } \beta \text {-glucan by } 30 \%-52 \% \text { in the } \\
\text { endosperm. }\end{array}$ & [53] \\
\hline TaCslF6 & CaMV $35 S$ & Wheat & N. benthamiana & $\mathrm{HE}$ & $\begin{array}{l}\text { Synthesize } \beta \text {-glucan approximately } 0.6 \%-2.0 \% \\
(w / w) \text { in leaves with a DP3/DP4 ratio of } 1.60 \text {. }\end{array}$ & {$[21]$} \\
\hline AsCslF6 & CaMV $35 S$ & Oat & N. benthamiana & $\mathrm{HE}$ & $\begin{array}{l}\text { Synthesize } \beta \text {-glucan approximately } 0.59 \% \\
(\mathrm{w} / \mathrm{w}) \text { in leaves with a DP3/DP4 ratio of } 1.09 \text {. }\end{array}$ & [21] \\
\hline ZmCslF6 & CaMV $35 S$ & Maize & N. benthamiana & $\mathrm{HE}$ & $\begin{array}{c}\text { Synthesize } \beta \text {-glucan approximately } 1.59 \% \\
(\mathrm{w} / \mathrm{w}) \text { in leaves with a DP3/DP4 ratio of } 1.07 \text {. }\end{array}$ & [21] \\
\hline SbCslF6 & CaMV $35 S$ & Sorghum & N. benthamiana & $\mathrm{HE}$ & $\begin{array}{l}\text { Synthesize } \beta \text {-glucan approximately } 3.8 \%-5.9 \% \\
(\mathrm{w} / \mathrm{w}) \text { in leaves with a DP3/DP4 ratio of } 0.93 \text {. }\end{array}$ & [21] \\
\hline
\end{tabular}

HE, heterologous expression; OE, overexpression; RNAi, RNA interference.

the endosperm of wheat [53], and the cslf6 knockout mutant has displayed more than $97 \%$ reduction of $\beta$-glucan in rice [46]. Recently, a series of CRISPR/Cas9-induced mutations in the members of the $C s l F / H$ gene family have been generated. $\beta$-Glucan has only been absent in the grain of cslf6 knockout lines, whereas cslf3, cslf9, and cslh1 knockout lines have similar $\beta$-glucan content to the wild-type [50]. Hence, CslF6 is a crucial $\beta$-glucan synthase gene for engineering the accumulation of $\beta$-glucan in cereals.

However, there is a dosage effect negatively correlating $\beta$-glucan levels with plant growth. Transgenic plants overexpressing CslF6 under the constitutive CaMV $35 S$ promoter have accumulated high-level $\beta$-glucan with severe growth and developmental defect $[45,47]$. The negative effects of elevated $\beta$-glucan accumulation on plant growth have been prevented by the spatial-temporal regulation of CslF6 expression under the control of senescence-associated promoter or endosperm-specific promoter [45, 47].

As mentioned above, the molar ratio (DP3/DP4) of $\beta$-glucan varies and is a unique feature of each cereal. The CslF6 from Brachypodium, wheat, and barley has produced $\beta$-glucan with a relatively high DP3/DP4 ratio, while CslF6 
from maize, oat, rice, and sorghum has generated $\beta$-glucan with a relatively low DP3/DP4 ratio. By generating a series of chimeric constructs between four CslF6 cDNAs, it has been found that the transmembrane helices 4 (TMH4) of the membrane pore region of CslF6 can control the DP3/DP4 ratio and the fine structure of $\beta$-glucan. Point mutation constructs have further confirmed the isoleucine-to-leucine (I/L) change in the TMH4 of CslF6 to be responsible [21]. Furthermore, the glycine-to-aspartic acid (G/D) difference between barley and sorghum in the catalytic region of CslF6 has also been defined to dramatically influence the DP3/DP4 ratio of $\beta$-glucan [58].

\section{Food Application of Cereal $\beta$-Glucan}

Recently, $\beta$-glucan has been widely applied as an emulsion stabilizer, thickening agent, fat substitute, and bioactive ingredient in the food industry due to its water solubility, viscosity, gelation property, and health benefits [1, 3, 59]. Some of these functional products are favored by consumers owing to their improved quality together with low cholesterol and hypoglycemia properties [60-62]. Notwithstanding, incorporating $\beta$-glucan into some food products is still a challenge due to the possible negative effects on the textural quality, sensory characteristics, and shelf life of foods $[63,64]$. The effects of $\beta$-glucan on food quality and consumer acceptance in various food products will be discussed in the following sections.

4.1. Traditional Chinese Food. Noodle is a traditional Chinese food made from refined wheat flour that is low in dietary fiber, vitamins, minerals, and other important nutrients [65]. Thus, various ingredients including $\beta$-glucan are added to improve the health benefits of wheat flour noodles. Noodle incorporated with $30 \%$ banana flour and $10 \%$ oat $\beta$-glucan has exhibited an increase in total dietary fiber and essential minerals, thereby decreasing the glycemic index and carbohydrate digestibility rate [66]. Oat flour, famous for its high $\beta$-glucan content, has also been supplemented to wheat flour to produce oat-fortified noodles. Noodle formulations containing $10 \%-30 \%$ oat flour have led to increased $\beta$-glucan content and noodle firmness together with decreased noodle lightness and color stability [67]. In addition, more than $50 \%$ of wholemeal oat flour (with highlevel $\beta$-glucan) has been added into wheat flour and other ingredients (compensating for diluted gluten) to make oatbased white salted noodles, resulting in increased pasting viscosities and noodle hardness [68].

Steamed bread (Mantou), another traditional Chinese staple food, is also made from refined wheat flour and accounts for $40 \%$ of wheat consumption in China [69]. Steamed bread incorporated with $30 \%$ barley flour has presented significant improvements in the amount of $\beta$-glucan (from $0.03 \%$ to $1.03 \%$ ), hardness, and chewiness, but decreases in the specific volume, brightness, and whiteness index of steamed bread [70]. Steamed bread with the addition of less than $3 \mathrm{~g} / 100 \mathrm{~g}$ oat $\beta$-glucan has produced a comparable overall consumer acceptance, while an oat $\beta$-glucan addition of $5 \mathrm{~g} / 100 \mathrm{~g}$ has reduced the consumer acceptance but decreased the in vitro starch digestibility and predicted glycemic index [71].

4.2. Milk Products. $\beta$-Glucan is a functional bioactive component in the production of yogurt. Yogurt incorporated with $\beta$-glucan has exhibited faster proteolysis, lower release of large peptides, and more free amino acids [72]. The addition of barley $\beta$-glucan $(0.5,1,1.5$, and $2 \%$, w/v) has significantly enhanced the separation, viscosity, texture profile, and sensory characteristics of full-fat yogurt during storage [62].

Oat milk has also increased the $\beta$-glucan content while maintaining the sensory evaluation similar to the control drink [73]. Nonetheless, the incorporation of oat $\beta$-glucan into milk is challenged by the thermodynamic incompatibility between milk proteins and $\beta$-glucan, thereby limiting its application $[64,74]$. Additionally, $\beta$-glucan has been used as a fat substitute to produce low-fat cheese, which has resulted in softer cheese with decreased melt time and sensory scores [75].

4.3. Baking Products. Nowadays, $\beta$-glucan is preferred as a thickening and structure-making agent applied in glutenfree bakery products due to its prohealth benefits. The application of oat $\beta$-glucan (with an optimized percentage of $2.63 \%$ ) in gluten-free yeast-leavened cake has achieved positive effects on texture, volume, and sensory acceptance [61]. Similarly, gluten-free yeast-leavened cake with 5\%-20\% high-in- $\beta$-glucan oat fiber powder has shown improved springiness, cohesiveness, porosity, and volume [76].

$\beta$-Glucan-enriched biscuits, containing $5.2 \mathrm{~g} / 100 \mathrm{~g}$ $\beta$-glucan from barley flour, have been more acceptable to consumers, with sensory responses being similar to the control [77]. The addition of $\beta$-glucan to bread has also been widely tested, but its effect on loaf volume, bread firmness, rate of staling, and consumer acceptance has varied depending on certain conditions, including molecular weight, concentration, and source of $\beta$-glucan $[63,78-81]$.

4.4. Meat Products. $\beta$-Glucan is applied as a fat substitute in some meat products, such as beef patties, burgers, and sausages. Oat $\beta$-glucan gel (13.45\%) can be effectively applied as a fat replacer in low-fat beef patties by retaining fat and moisture, thereby increasing the cooking yield [82]. The addition of inulin gel (IG) and oat $\beta$-glucan $(\beta \mathrm{G})$ mixtures (3\%-IG and $0.3 \%-\beta \mathrm{G}, 6 \%-\mathrm{IG}$ and $0.6 \%-\beta \mathrm{G}$ ) could be a valuable alternative to improve the stability, texture, and adhesiveness of low-fat meat emulsions [83]. Low-fat beef burgers, containing $2.2 \% \beta$-glucan, have exhibited improved texture parameters and cooking properties along with enhanced nutritional characteristics [84]. Oat $\beta$-glucan (OG) and marine collagen peptide (MCP) mixed gel (OG/MCP ratio $10: 1)$ in low-fat sausage (50\% fat reduced) has significantly increased the springiness and chewing, while the taste and overall palatability of such sausage have been comparable with those of the control [85]. 


\section{Conclusions and Future Perspectives}

$\beta$-Glucan from cereal grains is a valuable dietary fiber that has numerous health-promoting applications. Its health benefits and physicochemical characteristics are conducive to its application in various food products. In China, people pay considerable attention to health and functional food nowadays. The application of $\beta$-glucan in traditional Chinese food, such as noodles and steamed bread, is a trend. Nevertheless, wheat and rice, as the main food sources of humans, have a less amount of $\beta$-glucan compared with barley and oat. Therefore, future research should focus on improving the $\beta$-glucan content in wheat and rice grains. Molecular weight and molar ratio should also be considered due to their effects on the solubility and viscosity of $\beta$-glucan and subsequently on the final food products. With further studies on the $\beta$-glucan synthase gene family, it is promising to improve the $\beta$-glucan content and modify its molar ratio by marker-assisted breeding and molecular design breeding in the future.

\section{Data Availability}

All the data generated or analyzed during this study are included in this article.

\section{Conflicts of Interest}

All the authors declare that there are no conflicts of interest.

\section{Acknowledgments}

This work was supported by the Financial Fund of Hebei Province (F14E055611), HAAFS Agriculture Science and Technology Innovation Project (2019-4-8-3, 2019-4-1-2), S\&T Program of Hebei (C2019301089 and C2019301135), National Key Research and Development Project (2017YFD0100603, 2018YFD0300503), and Hebei Modern Agricultural Industry Technology System Innovation Team Construction (HBCT2018010201).

\section{References}

[1] B. Du, M. Meenu, H. Liu, and B. Xu, "A concise review on the molecular structure and function relationship of $\beta$-glucan," International Journal of Molecular Sciences, vol. 20, no. 16, p. 4032, 2019.

[2] G. Maheshwari, S. Sowrirajan, and B. Joseph, "Extraction and isolation of $\beta$-glucan from grain sources-A review," Journal of Food Science, vol. 82, no. 7, pp. 1535-1545, 2017.

[3] S. M. V. Mejía, A. de Francisco, and B. Bohrer, "A comprehensive review on cereal $\beta$-glucan: extraction, characterization, causes of degradation, and food application," Critical Reviews in Food Science and Nutrition, vol. 60, no. 21, pp. 3693-3704, 2020.

[4] A. Nakashima, K. Yamada, O. Iwata et al., " $\beta$-Glucan in foods and its physiological functions," Journal of Nutritional Science and Vitaminology, vol. 64, no. 1, pp. 8-17, 2018.

[5] Y. Fuse, M. Higa, N. Miyashita et al., "Effect of high $\beta$-glucan barley on postprandial blood glucose and insulin levels in type
2 diabetic patients," Clinical Nutrition Research, vol. 9, no. 1, pp. 43-51, 2020.

[6] M. Higa, Y. Fuse, N. Miyashita et al., "Effect of high $\beta$-glucan barley on postprandial blood glucose levels in subjects with normal glucose tolerance: assessment by meal tolerance test and continuous glucose monitoring system," Clinical Nutrition Research, vol. 8, no. 1, pp. 55-63, 2019.

[7] D. Xu, H. Liu, C. Yang et al., "Effects of different delivering matrices of $\beta$-glucan on lipids in mildly hypercholesterolaemic individuals: a meta-analysis of randomised controlled trials," The British Journal of Nutrition, vol. 125, no. 3, pp. 294-307, 2021.

[8] Y. Wang, S. V. Harding, S. J. Thandapilly, S. M. Tosh, P. J. H. Jones, and N. P. Ames, "Barley $\beta$-glucan reduces blood cholesterol levels via interrupting bile acid metabolism," British Journal of Nutrition, vol. 118, no. 10, pp. 822-829, 2017.

[9] A. Geller, R. Shreshtha, and J. Yan, "Yeast-derived $\beta$-glucan in cancer: novel uses of a traditional therapeutic," International Journal of Molecular Sciences, vol. 20, no. 15, p. 3618, 2019.

[10] M. Divya, M. Govindarajan, S. Karthikeyan et al., "Antibiofilm and anticancer potential of $\beta$-glucan-binding proteinencrusted zinc oxide nanoparticles," Microbial Pathogenesis, vol. 141, Article ID 103992, 2020.

[11] F. Sadeghi, F. Peymaeei, M. Falahati et al., "The effect of Candida cell wall beta-glucan on treatment-resistant LL/2 cancer cell line: in vitro evaluation," Molecular Biology Reports, vol. 47, no. 5, pp. 3653-3661, 2020.

[12] F. Peymaeei, F. Sadeghi, E. Safari et al., "Candida albicans beta-glucan induce anti- cancer activity of mesenchymal stem cells against lung cancer cell line: an in-vitro experimental study," Asian Pacific Journal of Cancer Prevention, vol. 21, no. 3, pp. 837-843, 2020.

[13] G. D. Brown and S. Gordon, "Immune recognition. A new receptor for $\beta$-glucans,” Nature, vol. 413, no. 6851, pp. 36-37, 2001.

[14] R. Mathews, A. Kamil, and Y. Chu, "Global review of heart health claims for oat beta-glucan products," Nutrition Reviews, vol. 78, no. S1, pp. 78-97, 2020.

[15] S. Jood and S. Kalra, "Chemical composition and nutritional characteristics of some hull less and hulled barley cultivars grown in India," Molecular Nutrition \& Food Research, vol. 45, no. 1, pp. 35-39, 2001.

[16] L. Munck, B. Møller, S. Jacobsen, and I. Søndergaard, "Near infrared spectra indicate specific mutant endosperm genes and reveal a new mechanism for substituting starch with $(1 \longrightarrow 3,1 \longrightarrow 4)$ - $\beta$-glucan in barley," Journal of Cereal Science, vol. 40, no. 3, pp. 213-222, 2004.

[17] A. Lazaridou and C. G. Biliaderis, "Molecular aspects of cereal $\beta$-glucan functionality: physical properties, technological applications and physiological effects," Journal of Cereal Science, vol. 46, no. 2, pp. 101-118, 2007.

[18] M. Colleoni-Sirghie, I. V. Kovalenko, J. L. Briggs, B. Fulton, and P. J. White, "Rheological and molecular properties of water soluble $(1,3)(1,4)-\beta$-d-glucans from high- $\beta$-glucan and traditional oat lines," Carbohydrate Polymers, vol. 52, no. 4, pp. 439-447, 2003.

[19] H. P. Ramesh and R. N. Tharanathan, "Carbohydrates-the renewable raw materials of high biotechnological value," Critical Reviews in Biotechnology, vol. 23, no. 2, pp. 149-173, 2003.

[20] J. R. Pritchard, G. J. Lawrence, O. Larroque et al., "A survey of $\beta$-glucan and arabinoxylan content in wheat," Journal of the Science of Food and Agriculture, vol. 91, no. 7, pp. 1298-1303, 2011. 
[21] S. A. Jobling, "Membrane pore architecture of the CslF6 protein controls $(1-3,1-4)-\beta$-glucan structure," Science Advances, vol. 1, no. 5, Article ID e1500069, 2015.

[22] W. Li, S. Cui, and Y. Kakuda, "Extraction, fractionation, structural and physical characterization of wheat $\beta$-D-glucans," Carbohydrate Polymers, vol. 63, no. 3, pp. 408-416, 2006.

[23] R. A. Ermawar, H. M. Collins, C. S. Byrt et al., "Distribution, structure and biosynthetic gene families of $(1,3 ; 1,4)-\beta$-glucan in Sorghum bicolor," Journal of Integrative Plant Biology, vol. 57, no. 4, pp. 429-445, 2015.

[24] D. E. Khoury, C. Cuda, B. L. Luhovyy, and G. H. Anderson, "Beta glucan: health benefits in obesity and metabolic syndrome," Journal of Nutrition and Metabolism, vol. 2012, Article ID 851362, 28 pages, 2012.

[25] R. A. Burton and G. B. Fincher, "Current challenges in cell wall biology in the cereals and grasses," Frontiers in Plant Science, vol. 3, p. 130, 2012.

[26] G. Goudar, P. Sharma, S. Janghu, and T. Longvah, "Effect of processing on barley $\beta$-glucan content, its molecular weight and extractability," International Journal of Biological Macromolecules, vol. 162, pp. 1204-1216, 2020.

[27] J. Ehrenbergerová, N. Březinová Belcredi, V. Psota, P. Hrstková, R. Cerkal, and C. W. Newman, "Changes caused by genotype and environmental conditions in beta-glucan content of spring barley for dietetically beneficial human nutrition," Plant Foods for Human Nutrition, vol. 63, no. 3, pp. 111-117, 2008.

[28] E. Dickin, K. Steele, G. Frost, G. Edwards-Jones, and D. Wright, "Effect of genotype, environment and agronomic management on $\beta$-glucan concentration of naked barley grain intended for health food use," Journal of Cereal Science, vol. 54, no. 1, pp. 44-52, 2011.

[29] T. Vasanthan and F. Temelli, "Grain fractionation technologies for cereal beta-glucan concentration," Food Research International, vol. 41, no. 9, pp. 876-881, 2008.

[30] K. Liu, F. T. Barrows, and D. Obert, "Dry fractionation methods to produce barley meals varying in protein, betaglucan, and starch contents," Journal of Food Science, vol. 74, no. 6, pp. C487-C499, 2009.

[31] P. S. Thondre, A. Shafat, and M. E. Clegg, "Molecular weight of barley $\beta$-glucan influences energy expenditure, gastric emptying and glycaemic response in human subjects," British Journal of Nutrition, vol. 110, no. 12, pp. 2173-2179, 2013.

[32] P. S. Thondre and C. J. K. Henry, "Effect of a low molecular weight, high-purity $\beta$-glucan on in vitro digestion and glycemic response," International Journal of Food Sciences and Nutrition, vol. 62, no. 7, pp. 678-684, 2011.

[33] Y. Wang, N. P. Ames, H. M. Tun et al., "High molecular weight barley $\beta$-glucan alters gut microbiota toward reduced cardiovascular disease risk," Frontiers in Microbiology, vol. 7, p. 129, 2016.

[34] T. J. Simmons, D. Uhrín, T. Gregson et al., "An unexpectedly lichenase-stable hexasaccharide from cereal, horsetail and lichen mixed-linkage $\beta$-glucans (MLGs): implications for MLG subunit distribution," Phytochemistry, vol. 95, pp. 322-332, 2013.

[35] R. A. Burton and G. B. Fincher, " $(1,3 ; 1,4)-\beta-D-G l u c a n s$ in cell walls of the poaceae, lower plants, and fungi: a tale of two linkages," Molecular Plant, vol. 2, no. 5, pp. 873-882, 2009.

[36] D. C. Doehlert and S. Simsek, "Variation in $\beta$-glucan fine structure, extractability, and flour slurry viscosity in oats due to genotype and environment," Cereal Chemistry Journal, vol. 89, no. 5, pp. 242-246, 2012.
[37] F. Han, S. E. Ullrich, S. Chirat et al., "Mapping of $\beta$-glucan content and $\beta$-glucanase activity loci in barley grain and malt," Theoretical and Applied Genetics, vol. 91, no. 6-7, pp. 921-927, 1995.

[38] K. Houston, J. Russell, M. Schreiber et al., "A genome wide association scan for $(1,3 ; 1,4)$ - $\beta$-glucan content in the grain of contemporary 2-row Spring and Winter barleys," BMC Genomics, vol. 15, no. 1, p. 907, 2014.

[39] K. Wei, D.-w. Xue, Y.-z. Huang, X.-l. Jin, F.-b. Wu, and G.-p. Zhang, "Genetic mapping of quantitative trait loci associated with $\beta$-amylase and limit dextrinase activities and $\beta$-glucan and protein fraction contents in barley," Journal of Zhejiang University SCIENCE B, vol. 10, no. 11, pp. 839-846, 2009.

[40] J. L. Molina-Cano, M. Moralejo, M. Elía et al., "QTL analysis of a cross between European and North American malting barleys reveals a putative candidate gene for $\beta$-glucan content on chromosome 1H," Molecular Breeding, vol. 19, no. 3, pp. 275-284, 2007.

[41] J. Li, M. Båga, B. G. Rossnagel, W. G. Legge, and R. N. Chibbar, "Identification of quantitative trait loci for $\beta$-glucan concentration in barley grain," Journal of Cereal Science, vol. 48, no. 3, pp. 647-655, 2008.

[42] H.-S. Kim, K.-G. Park, S.-B. Baek, and J.-G. Kim, "Inheritance of (1-3)(1-4)-beta-D-glucan content in barley (Hordeum vulgare L.)," Journal of Crop Science and Biotechnology, vol. 14, no. 4, pp. 239-245, 2011.

[43] X. Shu and S. K. Rasmussen, "Quantification of amylose, amylopectin, and $\beta$-glucan in search for genes controlling the three major quality traits in barley by genome-wide association studies," Frontiers in Plant Science, vol. 5, p. 197, 2014.

[44] R. A. Burton, S. M. Wilson, M. Hrmova et al., "Cellulose synthase-like $C s l F$ genes mediate the synthesis of cell wall $(1,3$; 1, 4)- $\beta$-D-glucans," Science, vol. 311, no. 5769, pp. 1940-1942, 2006.

[45] M. E. Vega-Sánchez, D. Loqué, J. Lao et al., "Engineering temporal accumulation of a low recalcitrance polysaccharide leads to increased C6 sugar content in plant cell walls," Plant Biotechnology Journal, vol. 13, no. 7, pp. 903-914, 2015.

[46] M. E. Vega-Sánchez, Y. Verhertbruggen, U. Christensen et al., "Loss of Cellulose synthase-like F6 function affects mixedlinkage glucan deposition, cell wall mechanical properties, and defense responses in vegetative tissues of rice," Plant Physiology, vol. 159, no. 1, pp. 56-69, 2012.

[47] R. A. Burton, H. M. Collins, N. A. J. Kibble et al., "Overexpression of specific $\mathrm{HvCslF}$ cellulose synthase-like genes in transgenic barley increases the levels of cell wall $(1,3 ; 1,4)$ $\beta$-D-glucans and alters their fine structure," Plant Biotechnology Journal, vol. 9, no. 2, pp. 117-135, 2011.

[48] T. Tonooka, E. Aoki, T. Yoshioka, and S. Taketa, "A novel mutant gene for $(1-3,1-4)-\beta$-D-glucanless grain on barley (Hordeum vulgare L.) chromosome 7H," Breeding Science, vol. 59, no. 1, pp. 47-54, 2009.

[49] S. Taketa, T. Yuo, T. Tonooka et al., "Functional characterization of barley betaglucanless mutants demonstrates a unique role for CslF6 in $(1,3 ; 1,4)-\beta$-D-glucan biosynthesis," Journal of Experimental Botany, vol. 63, no. 1, pp. 381-392, 2012.

[50] G. Garcia-Gimenez, A. Barakate, P. Smith et al., "Targeted mutation of barley $(1,3 ; 1,4)-\beta$-glucan synthases reveals complex relationships between the storage and cell wall polysaccharide content," The Plant Journal, vol. 104, no. 4, pp. 1009-1022, 2020. 
[51] M. S. Doblin, F. A. Pettolino, S. M. Wilson et al., "A barley cellulose synthase-like CSLH gene mediates $(1,3 ; 1,4)-\beta$-Dglucan synthesis in transgenic Arabidopsis," Proceedings of the National Academy of Sciences, vol. 106, no. 14, pp. 5996-6001, 2009.

[52] A. Little, J. G. Schwerdt, N. J. Shirley et al., "Revised phylogeny of the Cellulose Synthase gene superfamily: insights into cell wall evolution," Plant Physiology, vol. 177, no. 3, pp. 1124-1141, 2018.

[53] C. Nemeth, J. Freeman, H. D. Jones et al., "Down-regulation of the CSLF6 gene results in decreased $(1,3 ; 1,4)-\beta$-D-glucan in endosperm of wheat," Plant Physiology, vol. 152, no. 3, pp. 1209-1218, 2010.

[54] R. A. Burton, S. A. Jobling, A. J. Harvey et al., "The genetics and transcriptional profiles of the cellulose synthase-like HvCslF gene family in barley," Plant Physiology, vol. 146, no. 4, pp. 1821-1833, 2008.

[55] U. Christensen, A. Alonso-Simon, H. V. Scheller, W. G. T. Willats, and J. Harholt, "Characterization of the primary cell walls of seedlings of Brachypodium distachyon a potential model plant for temperate grasses," Phytochemistry, vol. 71, no. 1, pp. 62-69, 2010.

[56] L. Wang, K. Guo, Y. Li et al., "Expression profiling and integrative analysis of the CESA/CSL superfamily in rice," $B M C$ Plant Biology, vol. 10, no. 1, p. 282, 2010.

[57] M. Schreiber, F. Wright, K. Mackenzie et al., "The barley genome sequence assembly reveals three additional members of the CslF $(1,3 ; 1,4)$ - $\beta$-glucan synthase gene family," PLoS One, vol. 9, no. 3, Article ID e90888, 2014.

[58] G. Dimitroff, A. Little, J. Lahnstein et al., " $(1,3 ; 1,4)-\beta$-Glucan biosynthesis by the CSLF6 enzyme: position and flexibility of catalytic residues influence product fine structure," Biochemistry, vol. 55, no. 13, pp. 2054-2061, 2016.

[59] F. Zhu, B. Du, and B. Xu, "A critical review on production and industrial applications of beta-glucans," Food Hydrocolloids, vol. 52, pp. 275-288, 2016.

[60] D. Jaworska, M. Królak, W. Przybylski, and M. JezewskaZychowicz, "Acceptance of fresh pasta with $\beta$-glucan addition: expected versus perceived liking," Foods, vol. 9, no. 7, p. 869, 2020.

[61] S. Karp, J. Wyrwisz, and M. A. Kurek, "The impact of different levels of oat $\beta$-glucan and water on gluten-free cake rheology and physicochemical characterisation," Journal of Food Science and Technology, vol. 57, no. 10, pp. 3628-3638, 2020.

[62] R. Kaur and C. S. Riar, "Sensory, rheological and chemical characteristics during storage of set type full fat yoghurt fortified with barley $\beta$-glucan," Journal of Food Science and Technology, vol. 57, no. 1, pp. 41-51, 2020.

[63] F. Finocchiaro, B. Ferrari, A. Gianinetti et al., "Effects of barley $\beta$-glucan-enriched flour fractions on the glycaemic index of bread," International Journal of Food Sciences and Nutrition, vol. 63, no. 1, pp. 23-29, 2012.

[64] N. Sharafbafi, S. M. Tosh, M. Alexander, and M. Corredig, "Phase behaviour, rheological properties, and microstructure of oat $\beta$-glucan-milk mixtures," Food Hydrocolloids, vol. 41, pp. 274-280, 2014.

[65] J. L. Slavin, M. C. Martini, D. R. Jacobs, and L. Marquart, "Plausible mechanisms for the protectiveness of whole grains," The American Journal of Clinical Nutrition, vol. 70, no. 3, pp. 459s-463s, 1999.

[66] C. L. Choo and N. A. A. Aziz, "Effects of banana flour and $\beta$-glucan on the nutritional and sensory evaluation of noodles," Food Chemistry, vol. 119, no. 1, pp. 34-40, 2010.
[67] S. Mitra, L. Cato, A. P. James, and V. A. Solah, "Evaluation of white salted noodles enriched with oat flour," Cereal Chemistry, vol. 89, no. 2, pp. 117-125, 2012.

[68] T. T. L. Nguyen, R. G. Gilbert, M. J. Gidley, and G. P. Fox, "The contribution of $\beta$-glucan and starch fine structure to texture of oat-fortified wheat noodles," Food Chemistry, vol. 324, Article ID 126858, 2020.

[69] Y. Kim, W. Huang, H. Zhu, and P. Rayasduarte, "Spontaneous sourdough processing of Chinese Northern-style steamed breads and their volatile compounds," Food Chemistry, vol. 114, no. 2, pp. 685-692, 2009.

[70] S.-Y. Lin, H.-H. Chen, S. Lu, and P.-C. Wang, "Effects of blending of wheat flour with barley flour on dough and steamed bread properties," Journal of Texture Studies, vol. 43, no. 6 , pp. 438-444, 2012.

[71] L. Wang, F. Ye, L. Feng, F. Wei, and G. Zhao, "The effects of oat $\beta$-glucan incorporation on the quality, structure, consumer acceptance and glycaemic response of steamed bread," Journal of Texture Studies, vol. 48, no. 6, pp. 562-570, 2017.

[72] L. Rinaldi, L.-E. Rioux, M. Britten, and S. L. Turgeon, "In vitro bioaccessibility of peptides and amino acids from yogurt made with starch, pectin, or $\beta$-glucan," International Dairy Journal, vol. 46, pp. 39-45, 2015.

[73] G. Önning, A. Wallmark, M. Persson, B. Åkesson, S. Elmståhl, and R. Öste, "Consumption of oat milk for 5 weeks lowers serum cholesterol and LDL cholesterol in free-living men with moderate hypercholesterolemia," Annals of Nutrition and Metabolism, vol. 43, no. 5, pp. 301-309, 1999.

[74] N. Repin, M. G. Scanlon, and R. Gary Fulcher, "Phase behaviour of casein micelles and barley beta-glucan polymer molecules in dietary fibre-enriched dairy systems," Journal of Colloid and Interface Science, vol. 377, no. 1, pp. 7-12, 2012.

[75] G. Konuklar, G. E. Inglett, K. Warner, and C. J. Carriere, "Use of a $\beta$-glucan hydrocolloidal suspension in the manufacture of low-fat Cheddar cheeses: textural properties by instrumental methods and sensory panels," Food Hydrocolloids, vol. 18, no. 4, pp. 535-545, 2004.

[76] S. Karp, J. Wyrwisz, M. A. Kurek, and A. Wierzbicka, "The use of high-in- $\beta$-glucan oat fibre powder as a structuring agent in gluten-free yeast-leavened cake," Food Science and Technology International, vol. 25, no. 7, pp. 618-629, 2019.

[77] P. Vitaglione, R. B. Lumaga, C. Montagnese, M. C. Messia, E. Marconi, and L. Scalfi, "Satiating effect of a barley betaglucan-enriched snack," Journal of the American College of Nutrition, vol. 29, no. 2, pp. 113-121, 2010.

[78] Z. Mohebbi, A. Homayouni, M. H. Azizi, and S. J. Hosseini, "Effects of beta-glucan and resistant starch on wheat dough and prebiotic bread properties," Journal of Food Science and Technology, vol. 55, no. 1, pp. 101-110, 2018.

[79] K. M. Andrzej, M. Małgorzata, K. Sabina, O. K. Horbańczuk, and E. Rodak, "Application of rich in $\beta$-glucan flours and preparations in bread baked from frozen dough," Food Science and Technology International, vol. 26, no. 1, pp. 53-64, 2020.

[80] A. Skendi, C. G. Biliaderis, M. Papageorgiou, and M. S. Izydorczyk, "Effects of two barley $\beta$-glucan isolates on wheat flour dough and bread properties," Food Chemistry, vol. 119, no. 3, pp. 1159-1167, 2010.

[81] M. A. Kurek, J. Wyrwisz, S. Karp, M. Brzeska, and A. Wierzbicka, "Comparative analysis of dough rheology and quality of bread baked from fortified and high-in-fiber flours," Journal of Cereal Science, vol. 74, pp. 210-217, 2017.

[82] M. P. Piñero, K. Parra, N. Huerta-Leidenz et al., "Effect of oat's soluble fibre ( $\beta$-glucan) as a fat replacer on physical, 
chemical, microbiological and sensory properties of low-fat beef patties," Meat Science, vol. 80, no. 3, pp. 675-680, 2008.

[83] D. Álvarez and S. Barbut, "Effect of inulin, $\beta$-Glucan and their mixtures on emulsion stability, color and textural parameters of cooked meat batters," Meat Science, vol. 94, no. 3, pp. 320-327, 2013.

[84] R. Afshari, H. Hosseini, R. Khaksar et al., "Investigation of the effects of inulin and $\beta$-glucan on the physical and sensory properties of low-fat beef burgers containing vegetable oils: optimisation of the formulation using D-optimal mixture design," Food Technology and Biotechnology, vol. 53, no. 4, pp. 436-445, 2015.

[85] R. Fan, D. Zhou, and X. Cao, "Evaluation of oat $\beta$-glucanmarine collagen peptide mixed gel and its application as the fat replacer in the sausage products," PLoS One, vol. 15, no. 5, Article ID e0233447, 2020. 